\title{
O GRUPO CRIATIVO
}

\author{
THE CREATIVE GROUP
}

Sandra Augusta de Melo ${ }^{1}$

\begin{abstract}
RESUMO
As exigências e os fenômenos observados na criação publicitária em grupo fazem dela um protótipo, guardadas as proporções, de outras situações de trabalho e da vida cotidiana em que pessoas se reúnem para solucionar problemas. Este artigo analisa aspectos do funcionamento mental e das interações de um grupo de criação publicitária, partindo do depoimento de um de seus membros sobre como um anúncio foi criado em equipe. Sob a luz de algumas teorias psicanalíticas, busca-se entender a participação da mente individual dentro do grupo e compreender quais os aspectos do clima grupal que favorecem os processos criativos. Pode-se observar que no grupo criativo a mente grupal substitui 0 grupo internalizado, julgando as escolhas e liberando os indivíduos para um trabalho de associações livres e flutuantes. Os achados apontam a importância de que tais aspectos sejam investigados em outras situações de criação grupal.
\end{abstract}

Palavras-chave: criatividade; processo criativo; grupo.

ABSTRACT

The demands and phenomena observed in the creation of publicity in groups make it a prototype, retaining the proportions, from other work and daily life situations in which people come together to resolve problems. This article analyses aspects of the mental workings and the interaction of a group that creates publicity, starting with the deposition of one of its members as to how an advert was created by a team. From the point of view of certain psychoanalytical theories, we seek to understand the participation of the individual mind within the group and comprehend which are the aspects of the group environment that favour creative processes. It can be noted that in the creative group the group mind replaces the internalised group, judging the choices and freeing the individuals for free and floating associations. The findings indicate the importance of such aspects being investigated in other situations creation in groups.

Key words: creativity; creative process; group.

\section{INTRODUÇÃO}

Em trabalho anterior (Melo, 1999), buscou-se alguma compreensão sobre a criatividade através do estudo da criação artística, que é, na maioria das vezes, solitária e individual, e não utilitária, ou seja, não visa uma resposta a um problema dado, mas constitui a expressão objetiva da experiência de contato subjetivo com a realidade.

Este estudo não se prenderá à tarefa de definir criatividade, já que muitos são os autores que têm buscado este intento, a exemplo de Ostrower (1999), Alencar (1995). Wechsler (1993), Young (1985) dentre tantos outros. Entretanto, sem que seja necessário descartar outras definições, aqui nos ocuparemos da criatividade que apresenta "... um produto ou resposta ... criativos na extensão em que é tanto uma novidade quanto uma resposta apropriada, útil, correta ou valorizada com relação à tarefa que se tem em mãos..." (Amabile, 1983 apud Morais, 2001).

\footnotetext{
${ }^{1}$ Psicóloga da Universidade Federal de Uberlândia; Rua Pedro José Samora, 1.150 / 502, Bairro Santa Mônica Uberlândia, MG - 38408-624; saugusta@nanet.com.br
} 
Assim, neste artigo, pretende-se embrenhar por um campo mais aproximado da criatividade aplicada ao cotidiano, ou seja, a capacidade de dar respostas originais a questões de ordem prática. Além deste aspecto, tenciona-se especialmente abordar o processo criativo que é fruto da interação grupal, em que as mentes individuais formam uma sinergia buscando uma solução criativa para um dado problema.

Acredita-se que, este tipo de situação, em que um grupo se coloca diante de um problema concreto que requer produção de respostas genuínas, é algo comum às pessoas que são, cada vez mais, exigidas a serem criativas em grupo pelo mercado de trabalho. Entretanto, não é só no âmbito de trabalho que essa situação se impõe mas também no cotidiano do lar, da escola, e em todas as interações humanas em que há que se buscar soluções inovadoras para velhas e novas questões.

Para realizar a intenção aqui contida, buscou-se analisar e discutir um tipo de trabalho em grupo que é eminentemente criativo: a criação publicitária. Nele a criatividade é, explicitamente, um objetivo perseguido com caraterísticas similares àquela que nos é exigida no cotidiano: o novo deve surgir dentro de limites de viabilidade e praticidade impostos de antemão - muito embora, nesse tipo de trabalho, isso pareça intensificado pela urgência e pressões sofridas. Além disso, a criatividade publicitária se dá na interdependência de vários indivíduos e deve ser dirigida ao grupo mais amplo: a comunidade.

A grosso modo pode-se dizer que sempre há interação entre os profissionais que participam da criação de uma peça publicitária. Entretanto, de trabalho para trabalho, o nível de interação entre eles varia muito. Pode tanto ocorrer ao redator criar a chamada e conceber a idéia central e comunicá-la para o programador visual ou ser o diretor de arte que prossegue a partir disto, quanto um grupo (2, 3 ou mais pessoas) colocar-se diante de um problema para discuti-lo, e criarem juntos, trocando idéias.

De maneira geral, sempre há um grupo por trás da criação final, já que as peças envolvem tanto imagens como linguagem escrita e/ou falada, e estes trabalhos são realizados por especialistas nestas áreas. Isso sem falar da etapa de produção, em que participam ainda locutores, atores, diretores de VT, produtores etc., que têm inevitavelmente um toque pessoal no resultado final do trabalho, com maior ou menor expressão.

Entretanto, para restringir-se ao pequeno universo de discussão cabível num artigo como este, o raciocínio se limitará à etapa de criação propriamente dita, ou seja, àquela em que a peça publicitária é concebida, comumente designada como "criação", assim como também é chamado o espaço físico de trabalho dos profissionais da área.

A criação não sai do nada, e o criativo não é um deus absoluto de sua criação. Ela se relaciona ao grupo, às instituições e à cultura da qual emerge. Na propaganda, isso fica muito evidente, uma vez que ela é direcionada ao grupo social mais amplo.

Um criativo publicitário deve ter em mente os valores, hábitos, padrões de comportamento e ideais do público para o qual direciona seu trabalho, já que seu intento é atingi-lo em seu desejo de consumir ou criar nele novas atitudes (de consumo ou não).

Este aspecto aponta a necessidade de se contar, no indivíduo, com o grupo interno representativo de seu público. É a sua participação numa dada cultura que o habilita a saber se aquilo que produziu comunicará e atingirá seus objetivos. Em muitos casos conta-se com pesquisas para isto, entretanto, a sensibilidade do profissional em perceber as emoções da mente coletiva associadas àquilo que anuncia é determinante para o sucesso do trabalho (Martins, 1999).

Assim, a partir desse pequeno comentário sobre o trabalho da criação publicitária, podese perceber sua representatividade para as questões que se pretende discutir: os modos de funcionamento de uma equipe de criação que trabalha interagindo, tanto em termos de processos mentais individuais quando do psiquismo grupal.

Para se chegar à discussão do processo de criação grupal, é necessário tomar algumas idéias e teorias sobre o processo criativo. Partindo-se de algumas idéias da Psicanálise sobre o 
funcionamento mental operante na criatividade, pretende-se discutir a lida com os limites em sua contradição com a necessidade de buscar o novo e a relação disto com o grupo.

Deve-se advertir que, se a criatividade nos é algo misterioso, a criação em grupo oferece ainda mais desafios ao nosso entendimento. Mas o mistério não é o impedimento para a busca do conhecimento, é justamente aquilo que o desafia. A presente discussão se faz na expectativa de que novas questões possam ser suscitadas a partir disso e não pretende esgotar quaisquer dos pontos abordados.

\section{Algumas características da criação publicitária}

Parece necessário, antes de prosseguir, que algumas particularidades do trabalho criativo em publicidade sejam explicitadas, especialmente alguns pontos relativos às condições em que se dá, para uma melhor compreensão da discussão que se segue.

As limitações ao trabalho criativo publicitário derivam de questões técnicas, mercadológicas, éticas, de tempo, da intervenção direta do cliente e de outros profissionais na própria criação.

A disponibilidade de recursos financeiros do cliente e a interferência deste no trabalho são dois dos fatores mais limitadores e estressantes para o publicitário. O limite do investimento em produção definirá, por exemplo, o número de cores a serem usadas, o espaço que se pode ocupar numa publicação, a qualidade de uma produção em vídeo ou áudio, da mesma forma que o orçamento define, também, o número de inserções em mídia. Ou seja, o investimento financeiro do cliente impõe limites à criação e define até mesmo aspectos estéticos dela.

Ainda há o fato de que o trabalho deverá ser criado e produzido em determinado prazo, e muitas vezes imediatamente e deverá passar pela aprovação do cliente, ocasião em que será preciso convencê-lo da qualidade e da eficiência do trabalho em alcançar os objetivos que ele pretende frente ao público.

As pressões e a imperiosidade das demandas externas exigem a aquisição de um maior domínio consciente sobre o processo de produção da peça genuína, além daquele necessário ao domínio técnico do material, seja ele as palavras e a língua, ou o material gráfico e o computador. Muito embora envolva aspectos comuns à criação, tal qual ocorre na arte, o trabalho criativo publicitário é caracterizado pela urgência e é cercado de cautela, porque passará por muitos julgamentos, e o maior e mais importante deles será o atingimento dos objetivos junto ao público.

Mas, a despeito de todos estes fatores, o profissional deverá criar. E criar envolve um rompimento com amarras. É este momento, o da criação dentro da equipe publicitária, que nos interessa discutir e, para ilustrar a discussão, apresenta-se abaixo um trecho de um depoimento sobre como foi criada uma peça publicitária premiada em âmbito nacional. Tal depoimento foi tomado em entrevista gravada em áudio pela pesquisadora com um publicitário membro da equipe criativa de uma agência.

A seguir, passa-se, então, a discutir o processo de criação em grupo, lançando mão de teorias que melhor parecem contribuir para o seu entendimento.

Depoimento:

Era um anúncio para revista, formato oito, 21 por 28. Tínhamos 48 horas pra entregar finalizado... Um anúncio pra agência. Era preciso criar um anúncio sobre o acordo operacional com a (agência de São Paulo). O objetivo era valorizar esta conquista... Pra uma agência do interior de Minas é muito importante....

A gente partiu disso: da constatação de que a agência é uma agência do interior de Minas. Começamos a procurar um elemento que tivesse um caráter regional mineiro. Aí vão aparecendo as idéias, cada um fala uma idéia... Ah..., lembro que alguém lembrou "caipira"; procurou-se uma relação interior/exterior (gesto - dentro/fora do corpo). Até que a Adriana (estagiária) falou de queijo. Minas tem queijo. Queijo mineiro. Mas nada 
formulado sobre isso. O Jairo (diretor de arte) disse que gostava do queijo, que a forma era legal, o visual do queijo. A forma agradava.

Eu associei: o queijo é redondo, o mundo é redondo. A tem um acordo operacional com uma agência multinacional que tem unidades em mais de cem países do mundo. E... hã... O Jairo sugeriu desenhar o mapa múndi no queijo. Achei muito legal. Depois,... com isso, essas associações, estes caminhos, tendo o queijo e o mundo, fiz várias frases tentando um... um caminho.

- Você se lembra de algumas.

Não lembro mais (das frases).

- Muitas?

Umas quinze, vinte. Sempre faço assim, depois elimino. Escolho. Escolhi a expressão: "êta mundo véio sem porteira!"'

- (Riso) Hã?

(Sorri) É uma expressão caipira que traduz a conquista da agência. A frase é adequada. Assim: "ô coisa boa!"; expressa sentimento de conquista, é positiva e expressa tudo que queria. Sem porteira, não tem limites, barreiras, e a agência está conquistando espaço.

- Isso foi um trabalho mais isolado?

(Aceno com a cabeça)

- Depois...?

Aí falei com o Jairão: achei a chamada. O pessoal gostou.

- O pessoal?

É, o Jairão, a Adriana, o Júnior...

Aí depois é a execução, a criação é isso.

- Mas e a seqüência?

Ah, eu fiz o texto complementar. O diretor de arte buscou solução estética. Ele ia desenhar. Eu sugeri que ele fizesse em relevo, o mapa. Ele falou que não dava conta. $O$ Júnior disse que dava e ele fez, ficou muito bom. A gente foi ao mercado comprar o queijo (sorri). O Jairo acompanhou a foto. Depois pegou a foto, o texto ... fez a direção de arte.

- Como é isso?

Ah, é dar forma ao anúncio. Escolhe a tipologia, o tamanho, o tamanho da foto, do texto, essas coisas. Dá conjunto.

- E o resultado.

Todo mundo gostou. Foi medalha de prata no Colunistas (premiação), não houve ouro, então foi o melhor da categoria.

Após este relato, reúnem-se elementos para discutir

algumas idéias, para, entre teorias e dados empíricos, buscar algumas sínteses que possam abrir caminho à compreensão do fenômeno da criação em equipe e dos processos mentais nela envolvidos.

\section{Entre os limites e a liberdade necessária para criar}

Para criar é preciso liberar-se das limitações e mergulhar num campo de associações inusuais, na penumbra, num contato com derivações inconscientes do vínculo com o objeto, ao mesmo tempo em que esta mesma criação está, de antemão, restringida por exigências da realidade partilhada e concreta. Ela tem, então, duas exigências contraditórias a serem obedecidas pelo criativo: ser livre e ao mesmo tempo respeitar os limites definidos, ou seja, os parâmetros impostos à consecução da idéia.

É dentro de si que se busca o novo mas este se relaciona com o objeto. Esta é uma conclusão que se extrai da contribuição dos psicanalistas da segunda geração da escola inglesa: nem só o sujeito, nem só o objeto, o vínculo. Isto explica por que é tão importante para 
o criativo seu nível de informação; a riqueza de seu mundo mental amplia seu universo e as possibilidades sobre as quais criar.

O caso da criação publicitária, diferentemente da artística, mais livre, tem nas exigências externas limites muito claros com os quais se deve lidar, como já foi pontuado anteriormente. As condições são desafiadoras, já que é preciso trazer à tona o novo dentro de limites bastante claros e externos ao sujeito.

Entretanto, há um ponto no trabalho do criativo em que as limitações precisam ser esquecidas para que o novo surja. Este estado corresponde ao funcionamento esquizoparanóide (EP) tal qual derivado por Bion das idéias de Melanie Klein. São características de EP o estado de confusão e a sensação de caos que se experimenta enquanto se mantém em aberto uma questão na busca de uma solução inovadora, genuína ou mais próxima da verdade (o "0") (Bion, 1970; Lino-Silva, 1988; Tálamo, 1996).

É nestes momentos de caos que, diante da frustração causada pela presença da questão em aberto, surgem as respostas prontas e comuns. O criativo, ao contrário disso, é aquele que tolera este estado para emergir dele com o novo, ao invés de abraçar aquela resposta que está mais "à mão". (Lino-Silva, 1990).

Mas as limitações podem e devem ser retomadas quando o criativo elege um fato selecionado, se apossa da forma e, de volta, toma consciência de imagens visuais que lhe oferecem um caminho associativo.

O momento que corresponde à depressão (D) é aquele no qual surgem as unidades, as idéias, é o momento das sínteses e é também aquele ao qual deve se seguir uma seleção. Tal qual o pescador que devolve ao mar os frutos que não vai consumir ou comercializar, o criativo mantém na rede aquilo que corresponde às necessidades ou imposições de sua tarefa. Esta visão da depressão como um dos pólos da criação e do pensamento têm consonância com a descrição destes processos tal qual descreve Tálamo (1996).

No nível consciente procede-se, ainda a adaptações no material emergente. Quando não é possível aproveitar as idéias e imagens mediante comparação com os parâmetros externos, o processo de trânsito EP <=> D é retomado, as redes são novamente lançadas.

Outras etapas ainda se seguem no trabalho de busca do novo, e elas são igualmente importantes. O processo envolve, na seqüência, uma exposição ao grupo daquilo que foi produzido; etapa na qual ocorre uma apreciação segundo parâmetros do grupo em que se está inserido (grupo internalizado). Tálamo (1996:12) fala sobre a "publica-ação":

o primeiro estágio (PS <=> D) é essencialmente privado ao próprio indivíduo"... A publicação é algo que diz respeito à "...relação do indivíduo com seu grupo interno, seu 'senso comum' interno, e então de sua relação com seu grupo externo, que vai ou não aceitar, por meio do 'senso comum' do grupo, o que o indivíduo disse, fez, ou produziu..."

Nesse movimento, os indivíduos brincam com as idéias, e estas parecem ser pertencentes ao grupo como um todo e não a indivíduos particularmente. Não há críticas, mas uma busca pelas melhores respostas. Assim, a idéia surgida de um, pode ser tomada pelo outro, adaptada, complementada, torcida, invertida, sem que haja dores narcísicas para os membros.

Atua, neste momento, aquilo que a escola grupanalítica francesa (Anzieu, 1978) chama psiquismo grupal. O relaxamento da censura delata que a equipe de criação funciona em substituição ao grupo internalizado, e as melhores idéias colocadas pelos indivíduos são abraçadas pelos outros membros.

\footnotetext{
${ }^{2}$ Aqui a autora usa PS ao invés de EP por ter optado por adotar as iniciais tais quais são usadas no idioma inglês.
} 
A mente grupal criativa funciona de forma harmoniosa. Não há julgamento, mas eleição das melhores idéias mediante análise, e estas idéias eleitas são testadas como condutoras na linha de associações.

Neste caso, o próprio grupo é o senso comum. O indivíduo, inserido num clima receptivo e de aceitação, pode funcionar mais livre das limitações internalizadas, pois conta com o grupo criativo, real e externo para fazer este papel.

Assim, as novas idéias podem circular mais livremente na mente individual, pois serão submetidas à apreciação de um grupo externo crítico mas sintonizado com o espírito criativo, ou seja, comprometido com a busca do novo.

A equipe criativa parece sustentar-se por certo tempo na seta de mão dupla do esquema EP $<=>D$, num ir e vir que é próprio do pensamento criativo e de toda produção humana. $O$ grupo sustenta o paradoxo que é operar a despeito da contradição que significa estar submetido a restrições e liberar-se dos limites para criar, atribuindo a função do grupo internalizado ao grupo real, diminuindo assim a pressão interna inerente ao processo criativo que, a partir disso, flui mais fértil e rapidamente.

A criação se dá sempre no grupo, mesmo porque "o aparelho psíquico 'individual' é, ele próprio, constituído como interiorização duma organização grupal" (Kaës, 1978:68). A criação parte e retorna ao grupo que fornece elementos para a criação, e é também o lugar para onde ela irá retornar. Mente individual e mente grupal interagem de forma circular, até que o produto seja satisfatório a todos.

No caso descrito no depoimento, a criação nasceu do grupo em interação, as melhores idéias são incorporadas pelos indivíduos e passam a povoar suas mente em suas associações: o grupo se deixa conduzir por um fio comum, ao mesmo tempo em que cada qual mergulha em busca de respostas no seu próprio universo mental.

A situação parece paradoxal: um grupo de trabalho opera de forma convergente, do ponto de vista do pensamento. Uma equipe de criação, entretanto, deve funcionar de forma divergente para ser criativa. Convergir neste caso é pensar divergentemente - abandonando o óbvio para encontrar novas respostas - e retornar ao grupo com o que pode ser associado, para encontrar ali, na própria formação do grupo, um funcionamento equivalente ao princípio secundário - princípio de realidade - que arremeda uma função egóica.

Há uma forma de sintonia no grupo, necessária para a realização da tarefa. Algo acontece no psiquismo grupal que supera a possibilidade de explicação a partir das individualidades. Isto é conhecido na teoria da dinâmica de grupo como "sinergia". Entretanto, este termo nomeia, mas pouco esclarece ou explica do fenômeno.

Freud (1921) aplica ao estudo de fenômenos de massa o termo "contágio" para designar a facilidade com que os estados emocionais se disseminam entre as pessoas em grupo. Nos pequenos grupos isto pode ser observado quando um tipo de angústia torna-se dominante, permeando o psiquismo grupal, envolvendo todas as pessoas que participam de uma reunião, seja ela ou não uma sessão terapêutica.

Qual é a sintonia, o estado emocional necessário a um grupo que cria junto? E, no caso em questão, para que realize a tarefa de criar dentro de limites, numa situação paradoxal?

Se pensado a partir do modelo freudiano da primeira tópica, o que ocorre aos membros do grupo de criação é algo parecido com uma dupla presença. Na "nata" que se forma entre eles, circula um mesmo fio de associações norteados por dados de realidade, mas sob esta nata, cada qual percorre livremente e em profundidade o próprio universo mental em busca de representações.

O clima na equipe de criação é permeado por bom humor, brincadeiras e cumplicidade, embora com seriedade. Pode-se compreender que o grupo criativo relaciona-se com a realidade de forma transicional, ou melhor dizendo, as mentes coabitam um espaço transicional tal qual descrito por Winnicott (1968), ao mesmo tempo objetivo e subjetivo, real e irreal, ou seja, a criação grupal acontece num espaço intermediário, no nível simbólico.

Com este tipo de funcionamento, os participantes de um grupo de criação têm como um dos instrumentos o insight, compreendido como um mergulho relâmpago ao fundo de si, ou 
como a emergência quase espontânea de algo guardado nas profundezas da mente. 0 profissional criativo que exercita diariamente esta sua propriedade, parece adquirir uma capacidade de insight, uma habilidade em desviar-se do óbvio e em "pescar" associações mais genuínas.

O estado de mente necessário à produção de insights no grupo, de forma similar ao indivíduo, parece ser o relaxamento e a suspensão provisória da atenção no fato dado; o problema deve ficar momentaneamente suspenso e em aberto, enquanto o grupo viaja num estado emocional trazido por uma idéia. No caso relatado, a "mineirice", conclamando um narcisismo grupal/regionalista.

As idéias se sucedem de forma natural, como associações livres e flutuantes no grupo, até que uma é encontrada e adotada como caminho. A partir do momento em que o queijo mineiro surge como um simbolismo, sua imagem é aceita e uma linha começa a costurar as associações do grupo: "o mundo é redondo" é trazido pela forma do queijo e imediatamente associado ao fato de a agência ter acordos por vários países. O "mapa-múndi" surge de carona na idéia de mundo, com a imagem do mundo no queijo.

O redator busca frases que possam traduzir o que se quer dizer com as imagens: "êta mundo veio sem porteira" é a escolhida. O queijo e o mundo, Minas e o mundo sem limites traduzem a idéia da conquista da agência.

As associações trazem do universo mental elementos ao mesmo tempo novos e conhecidos; uma linha as costura. O universo é ilimitado, e infinitas linhas são possíveis, muitos planos podem ser traçados. Mas quando isso é feito de forma genuína, tem um efeito estético, tanto para o criador quanto para o espectador, porque traz um arranjo surpreendente .

A linha criativa é peculiar. Se uma linha for muito rígida, não há novo; se for muito frouxa, não há limites para as associações. Bion (1967) desenvolveu na teoria das transformações uma forma de compreendê-la: as rígidas são feitas por todo mundo, as em alucinose não são acessíveis ou partilháveis, mas as projetivas são aquelas que carregam algo de seu autor, em última instância, algo do universo mental do indivíduo que se formou em perspectiva, tendo em um eixo a cultura em que ele se insere e, em outro, seu modo particular de estar no mundo.

A criação publicitária recebe no $j o b^{3}$ indicações de onde chegar. Os criativos constróem o caminho, tecem a linha. De certa forma, isto indica o que será trazido à memória: a criação mantém um compromisso com o nexo, com a realidade compartilhada.

Este nexo e esta realidade orientam as associações da mesma forma que Kasparov diante do Deep Blue, o computador enxadrista, tinha que percorrer e analisar um menor número de jogadas possíveis, enquanto ao computador era necessário listar todas as possibilidades: no caso do criativo um "veio" é escolhido para mergulhar no mundo das associações infinitas.

No caso do jogo de xadrez, um espaço limitado, 64 casas e regras compõem um mundo restrito. As possibilidades são esgotáveis. Para a mente é diferente, o universo mental é infinito, e a mente criativa.

\section{CONSIDERAÇÕES FINAIS}

O modo de operação do processo criativo grupal observado na publicidade pode ser aplicado para compreender situações em que uma nova resposta ou solução é requerida, ainda que como nova não se entenda original, mas apenas não conhecida anteriormente por um grupo de trabalho.

A lida com as limitações é inerente à criação. Até mesmo o artista encontra limites na própria matéria-prima (tintas, argila, palavras etc.) para dar forma à sua obra. $\mathrm{Na}$ arte,

\footnotetext{
3 Job: termo que se utiliza para designar um tipo de ordem de serviço na qual consta o que se espera do trabalho, o que se pode gastar, entre outros dados. Em geral, a ordem é redigida pelo atendimento da agência mediante seus contatos com o cliente.
} 
entretanto, não há imposições outras que não as ligadas à oposição oferecida pela matéria na expressividade do artista, já que ela é uma expressão mais fiel da intuição e, por isso, o protótipo de todos os processos criativos quanto ao rompimento de limites (Melo, 1999).

Enquanto a experiência artística é muitas vezes compreendida como a própria ruptura de limites, nas artes aplicadas (aqui se inclui a publicidade), os limites são opressivos e irrefutáveis. Isso a aproxima das experiências cotidianas que nos requerem novas respostas para os problemas.

Sempre que se vai conceber um projeto, sempre que o pensamento elabora o planejamento de uma ação - o que para Freud (1911) é a própria definição de pensamento - é preciso lidar com as previsões sobre sua realização e criar formas de superar, burlar, transgredir os limites impostos, ou mesmo de usar a mesma força desses limites para a realização da obra.

Para todo ser humano que se submete à cultura, que passa pela educação formal, que conheceu leis, normas, regras, lógica, criar consiste em romper com o aprendido para retomálo depois. Sem os limites apreendidos, a criação não tem lugar no grupo; sem romper com o que se aprendeu do grupo, ainda que momentaneamente, não há criação. Criar é trazer a novidade, modificando, ainda que seja por acréscimo, aquilo que se aprendeu.

A criação em grupo pode diminuir o sofrimento psíquico inerente à criação e, ao mesmo tempo, propiciar condições para que a qualidade da produção (criatividade) seja melhorada, e o tempo gasto diminuído. Isso ocorre quando o grupo funciona sob um tipo de cisão, que mantém o lado livre, ilógico, mais próximo do inconsciente e do id dos indivíduos, protegido. Enquanto isso, o psiquismo grupal assume o princípio de realidade, que considera as regras, a lógica, os padrões, os valores, próprios da vida consciente e das atividades egóicas e superegóicas.

O entendimento da criação publicitária, tal qual mostra o presente estudo, aponta ainda um tipo de circulação favorável à formação de equipes criativas: o estabelecimento de um espaço permissivo ao rompimento com limites do real concreto e a liberdade individual, momentânea e instantânea, para que os limites sejam retomados em seguida e, mais uma vez, discutidos no seio do grupo.

O grupo criativo é aquele em que há viabilização de um funcionamento paralelo de consciente e inconsciente, de objetividade e subjetividade, de internalidade e externalidade, coexistindo na consecução da tarefa. É um grupo que tolera contradições momentâneas e que seleciona, pela função consciente e conhecimento das regras e da cultura, os elementos surgidos mediante a suspensão dos limites impostos por estas mesmas regras e cultura.

Há muito, ainda, para ser descoberto e discutido acerca do tema proposto. Espera-se, entretanto, que a presente análise possa suscitar questões e despertar interesse para pesquisas alinhadas.

\section{REFERÊNCIAS}

Alencar, E. M. (1995). Criatividade. Brasília: UNB.

Amabile, T. M. (1983). The social psychology of creativity. New York: Springer-Verlag. Apud Morais, E. R. (2001) O redespertar da criatividade: intervenção e avaliação através de um programa de desenvolvimento para estudantes de arquitetura. Uberlândia. Dissertação de mestrado: Centro Universitário do Triângulo UNIT.

Anzieu, D. (1978). O monitor e sua função interpretante. Em D. Anzieu. (Org), O trabalho psicanalítico nos grupos. p. 74-107, Lisboa: Moraes.

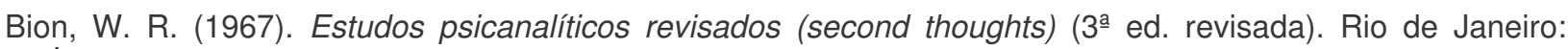
Imago.

Bion, W. R. (1970) A atenção e interpretação: acesso científico à intuição em Psicanálise e grupos. Rio de Janeiro: Imago.

Freud, S. (1911). Formulações sobre os dois princípios de funcionamento mental (Edição Standard Brasileira). Rio de Janeiro: Imago.

Freud, S. (1921). Psicologia de grupo e a análise do ego (Edição Standard Brasileira). Rio de Janeiro: Imago. 
Käes, R. (1978). Seminários 'analíticos' de formação: situação social-limite da instituição. Em D. Anzieu (Org.), O trabalho psicanalítico nos grupos (p. 15-73). Lisboa: Moraes.

Lino-Silva, M. E. (1988). Pensando o pensar com Bion. São Paulo: M. G. Editores.

Lino-Silva, M. E. (1990). A possibilidade de criar. Estudos de Psicologia, 7 (2), 54-72.

Martins, J. (1999). A natureza emocional da marca: como escolher a imagem que fortalece a sua marca. São Paulo: Negócio.

Melo, S. A. (1999). A transfiguração criativa da realidade. Campinas. Tese de doutorado. Pontifícia Universidade Católica de Campinas.

Ostrower, F. (1999). Criatividade e processos de criação. Petrópolis: Vozes.

Tálamo, P. B. (1998). Da ausência de forma à forma (PS $<=>$ D à pública-ação). Em L.C. U. Junqueira Filho (Org.), Silêncios e luzes: sobre a experiência psíquica do vazio e da forma (p. 71-86). São Paulo: Casa do Psicólogo.

Winnicott, D. W. (1968). O brincar e a realidade. Rio de Janeiro: Imago.

Winnicott, D. W. (1971). Natureza humana. Rio de Janeiro: Imago.

Weschsler, S. M. (1993). Criatividade: descobrindo e encorajando. Campinas: Editorial Psy.

Young, J. G. (1985). What is creativity? The Journal of Creative Behavior, 19(2), 77-87. 